\title{
PERANCANGAN APLIKASI INVENTORY SEPATU PADA GUDANG MELKY MARILYN BERBASIS JAVA NETBEANS
}

\author{
Anggie Triamsih ${ }^{1}$, Eko Harli ${ }^{2}$, Lukman ${ }^{3}$ \\ Program Studi Teknik Informatika, Fakultas Teknik dan Ilmu Komputer, \\ Universitas Indraprasta PGRI \\ Jalan Raya Tengah No 80, Kelurahan Gedong, Pasar Rebo, Jakarta Timur \\ anggietriamsih7@gmail.com¹, ekoharli@gmail.com², 1kmnaja51@gmail.com ${ }^{3}$
}

\begin{abstract}
Abstark
Persediaan barang merupakan sistem yang esensial untuk menunjang proses bisnis pada suatu perusahan, sehingga harus efisien dan efektif untuk mengetahui ketersediaan barang pada suatu perusahaan. Tujuan dari penelitian ini adalah untuk mempermudah pegawai melakukan proses pendataan barang atau sistem inventory pada gudang Melky Marilyn, sehingga menghasilkan informasi yang lebih akurat. Semua proses sebelumnya diolah secara manual sehingga sering mengalami kesalahan dan ksesulitan saat merekap data laporan stok barang sehingga terkadang mengalami kesalahan dalam ketersediaan stok barang. Metode penelitian yang digunakan oleh peneliti adalah metode waterfall yaitu model pengembangan sistem yang dilakukan secara sistematis atau berurut. Aplikasi ini dibuat dengan menggunakan java desktop dan database MySQL. Adapun hasil dari penelitian ini adalah sistem yang terkomputerisasi sehingga mempermudah proses pendataan barang untuk mengelola stok barang yang ada, mengurangi kekeliruan dan kehilangan data.
\end{abstract}

Kata Kunci: Aplikasi, Inventory, Java Netbeans, MySQL

\begin{abstract}
The supply of goods is an essential system to support business processes in a company, so it must be efficient and effective to know the availability of goods in a company. The purpose of this study is to make it easier for employees to do the process of collecting goods or inventory systems at Melky Marilyn warehouse, thus producing more accurate information. All previous processes are processed manually so that they often experience errors and errors when they collect stock report data so that sometimes experiencing errors in the availability of goods stock. The research method used by researchers is the waterfall method, which is a model of system development that is done systematically or in sequence. This application is created using java desktop and MySQL database. The results of this study are computerized systems that make it easier to collect goods to manage existing stock of goods, reduce errors and data loss.
\end{abstract}

Keywords: Application, Inventory, Java Netbeans, MySQL

\section{PENDAHULUAN}

Pada era teknologi informasi saat ini, kecepatan pengolahan dan penyampaian informasi memiliki peran yang sangat penting bagi setiap perusahaan atau suatu instansi untuk meningkatkan produktifitas pekerjaan, waktu dan biaya. Banyaknya data maupun informasi yang harus diolah tidak memungkinkan untuk melakukannya secara manual. Peran serta teknologi menjadikan pengolahan informasi menjadi semakin mudah. Gudang Melky Marilyn merupakan sebuah usaha yang bergerak di bidang fashion wanita khususnya sepatu Selama ini untuk pengolahan data persediaan sepatu masih dilakukan secara manual oleh admin gudang yaitu untuk pendataan barang masuk dan keluar, sehingga masih terjadi kesalahan dalam perhitungan barang, kesulitan dalam pencatatan dan pembuatan laporan barang masuk dan keluar juga stok yang tersedia. Gudang juga membutuhkan suatu sistem yang berguna mengolah data, menyimpan data, melihat kembali data dan manyampaikan infomasi yang baik, salah satunya adalah memiliki keakuratan data. Untuk memenuhi kebutuhan tersebut, maka yang harus dilakukan adalah memanfaatkan teknologi informasi seperti komputer beserta aplikasi sistem informasi untuk mempermudah dalam mengolah data dan mengurangi resiko kehilangan data dan juga data yang tidak akurat.

Dengan adanya masalah tersebut maka dibutuhkan suatu aplikasi yang dapat mempermudah proses pendataan dan mengurangi kesalahan data yaitu aplikasi persediaan barang yang mudah di akses oleh warehouse melky Marilyn. Inventory merupakan yang mengelola data persediaan di gudang, 
sistem ini harus dapat memberikan informasi seperti penerimaan barang, pengeluaran barang yang dapat mempermudah kerja user (Mardison, 2017). Tujuan dari penelitian ini antara lain untuk mempermudah pengguna dalam mengelola dan mendata ketersediaan stok barang barang yang masuk maupun keluar, Mempercepat proses pendataan stok barang dengan menggunakan sistem informasi inventory agar memperoleh data yang tepat dan akurat. Berdasarkan hal tersebut, maka penulis tertarik membuat dengan "Perancangan Aplikasi Inventory Sepatu Pada Warehouse Melky Marilyn".

\section{PENELITIAN RELEVAN}

Penelitian relevan pertama yang peneliti ambil yaitu dari jurnal yang berjudul "Perancangan Sistem Informasi Inventory Spare Part Elektronik Berbasis Web Php" (Studi CV. Human Global Service Yogyakarta) dengan nomor ISSN: 2338-5197 dengan nama peneliti Mhd Bustanur Rahmad, Tedy Setiady pada tahun 2014, dimana pada penelitian ini menjelaskan bahwa CV. Human Global Service masih melakukan pencatatan barang dengan menggunakan sistem secara manual, untuk mengetahui data stok barang serta pembuatan laporannya masih dengan cara penulisan di buku, maka waktu yang dibutuhkan untuk proses pembuatan laporan lebih lama dan kurang efektif, maka dibutuhkan aplikasi dalam pengolahan data persediaan barang khususnya persediaan spare part serta laporan yang terkomputerisasi agar pencatatan lebih cepat. (Setiady \& Rahmad, 2014).

Sedangkan penelitian kedua diambil dari jurnal yang berjudul "Penerapan Metode Economic Order Quantity Pada Rancangan Aplikasi Inventory Control System" dengan nomor ISSN: 2580-0760 dengan nama peneliti Stela Veranitaa, Mercurius Broto Legowo, dimana hasil dari penelitian produk terapan ini adalah suatu aplikasi sistem yang mempermudah para pengguna sistem untuk dapat mengendalikan persediaan yang dimiliki dengan cepat. Perancangan aplikasi sistem dalam penelitian ini dengan menggunakan pendekatan Unified Modeling Language (UML) Dalam penyelesaian berbagai masalah dalam pengendalian persediaan peneliti menerapkan metode Metode Economic Order Quantity (EOQ) dalam aplikasi sistem kontrol persediaan (Veranita \& Legowo, 2018).

\section{METODE PENELITIAN}

Metode pada penelitian ini adalah metode waterfall yang merupakan suatu metode yang memiliki ciri khas bahwa setiap fase harus dikerjakan terlebih dahulu (Nugraha, Syarif, \& Dharmawan, 2018). Metode waterfall sering dinamakan siklus hidup klasik (classic life cycle), dimana hal ini menggambarkan pendekatan yang sistematis dan juga berurutan pada pengembangan perangkat lunak. Adapun penjelasan mengenai alur dari penelitian yang digambarkan melelaui sistem waterfall:

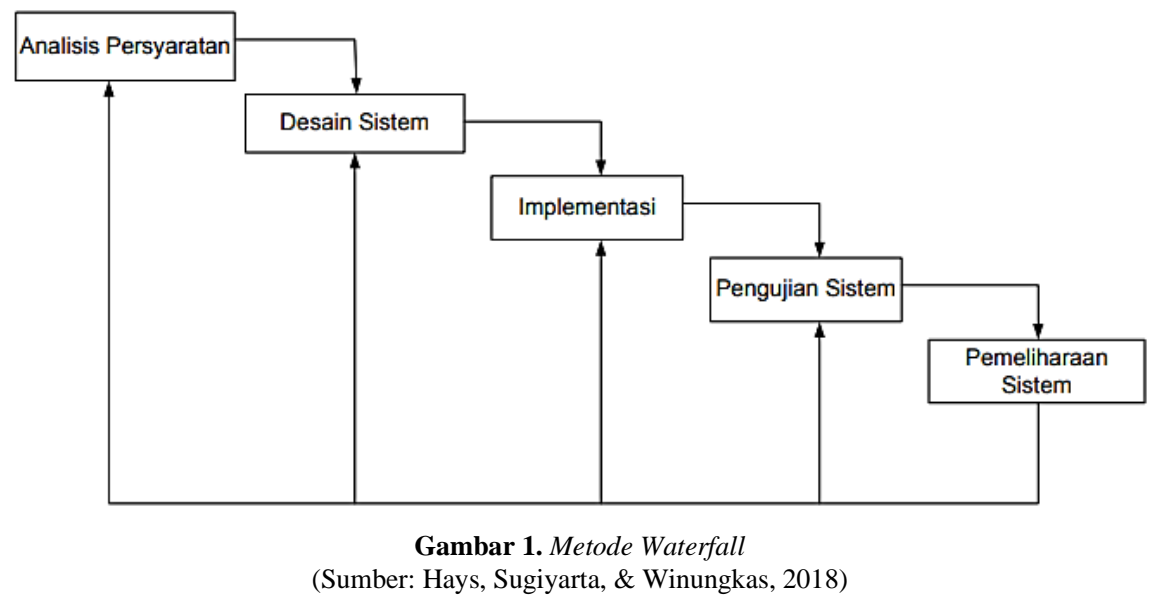

1. Analisis Persyaratan

Pada tahap ini seluruh kebutuan aplikasi harus bisa didapatkan, termasuk di dalamnya fungsi aplikasi yang diharapkan, penetapan fitur pada aplikasi dan batasan dari aplikasi. 
2. Desain Sistem

Tahapan ini dilakukan sebelum proses coding. Proses ini bertujuan untuk memberikan gambaran apa yang seharusnya dikerjakan dan bagaimana tampilannya. Tahap ini membantu dalam menspesifikasikan kebutuhan hardware dan sistem.

3. Implementasi

Dalam tahap ini dilakukan pemrograman. Hasil dari desain perangkat lunak akan direalisasikan sebagai satu set program atau unit program.

4. Pengujian Sistem

Di tahap ini dilakukan penggabungan program yang sudah dibuat dan dilakukan pengujian untuk mengetahui apakah software yang dibuat telah sesuai dengan desain.

5. Pemeliharaan Sistem

Ini merupakan tahap terakhir dalam model waterfall. Software yang sudah jadi dijalankan serta dilakukan pemeliharaan.

\section{Metode Pengumpulan Data}

Metode pengumpulan yang dilakukan dalam proses ini yaitu berupa Pengamatan Langsung (Observasi) Observasi diartikan sebagai pengamatan dan pencatatan secara sistematis terhadap gejala yang tampak pada objek penelitian. Observasi adalah salah satu teknik pencarian data yang paling efektif untuk pemahaman suatu sistem (Indrajani, 2015). Pengamatan dan pencatatan yang dilakukan terhadap objek di tempat terjadi yaitu Warehouse Melky Marilyn. Wawancara (Interview) Pengartian wawancara bisa dikategorikan sebagai percakapan dengan maksud tertentu. Percakapan dilakukan oleh kedua belah pihak, yaitu pewawancara (interviewer) yaitu yang memberikan jawaban dari pertanyaan-pertanyaan.

\section{HASIL DAN PEMBAHASAN}

Dari hasil penelitian yang penulis lakukan, maka penulis dapat menganalisa permasalahan yang ada di Warehouse Melky Marilyn. Adapun permasalahan yang ada adalah:

1. Dalam sistem pendataan barang yang sudah berjalan, penginputan data barang masih dilakukan secara manual, sehingga rawan terjadi kekeliruan data dan kehilangan data.

2. Sistem laporan pada warehouse yang sudah berjalan belum optimal karena laporan masih menjadi satu dengan data-data barang masuk dan keluar sehingga kurang efisien dan memperlambat pekerjaan.

3. Sistem pengolahan data inventory yang belum memiliki database menyebabkan data-data rentan hilang.

Alternatif penyelesaian masalah yang akan penulis buat adalah dengan membuat program aplikasi inventory secara terkomputerisasi, untuk mempermudah dalam proses pengolahan data. Program aplikasi ini akan dibuat dengan menggunakan bahasa pemograman java dan menggunakan database MySQL. Data-data yang dikelola akan di simpan dalam database. Dengan penyimpanan data dalam database ini diharapkan mampu mempermudah dalam proses pencarian, penyimpanan dan pengolahan data dengan aman. Aplikasi inventory yang akan dibuat juga akan mempermudah dalam penyusunan laporan karena data-data yang dibutuhkan ada didalam system dan dapat dicari dengan mudah. Sistem ini juga akan mempermudah dalam pekerjaan bagian gudang, karena proses pengolahan data-data akan dibuat menjadi lebih cepat dan mudah. 


\section{Diagram Konteks Sistem Yang Diusulkan}

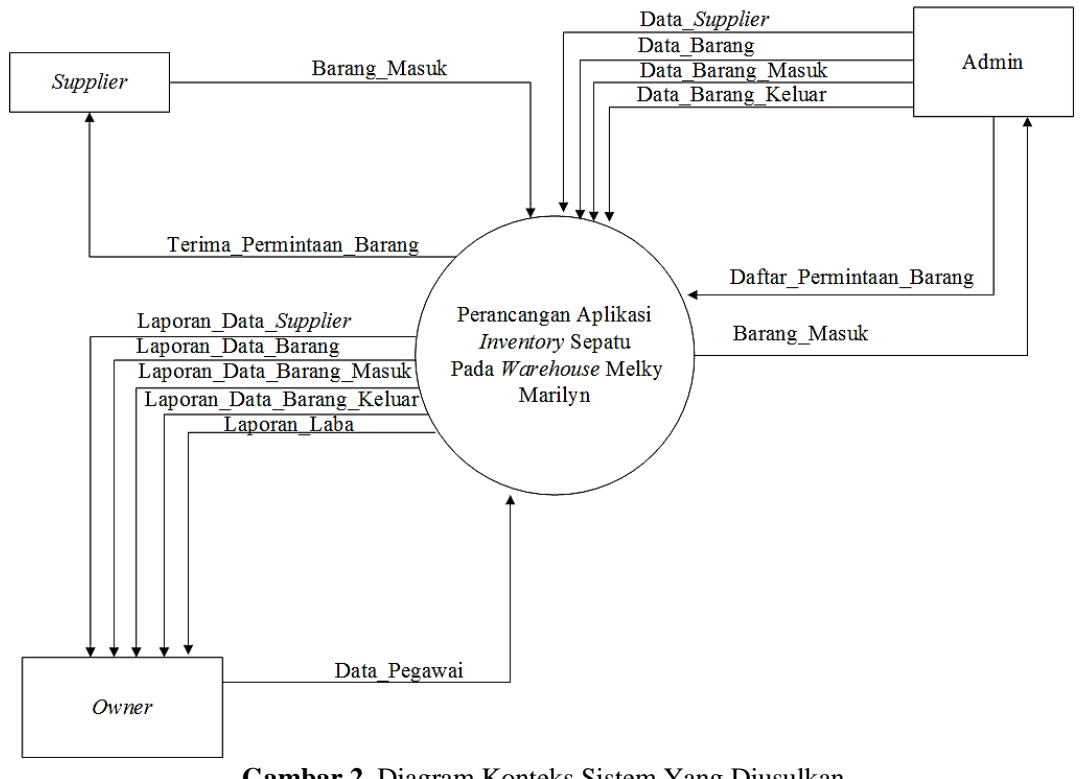

Gambar 2. Diagram Konteks Sistem Yang Diusulkan

\section{Diagram Nol Sistem Yang Diusulkan}

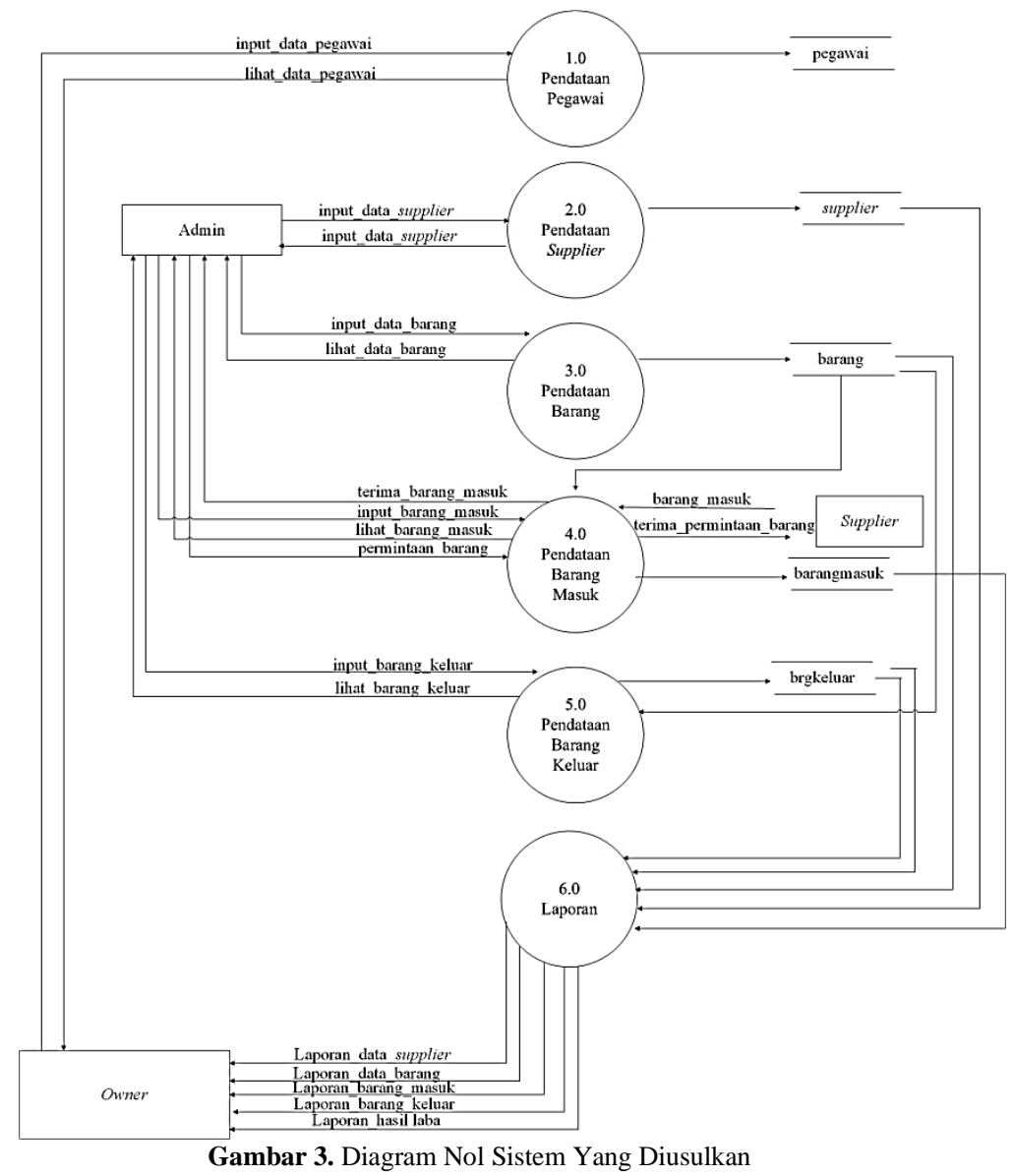




\section{Entity Relationship Diagram (ERD)}

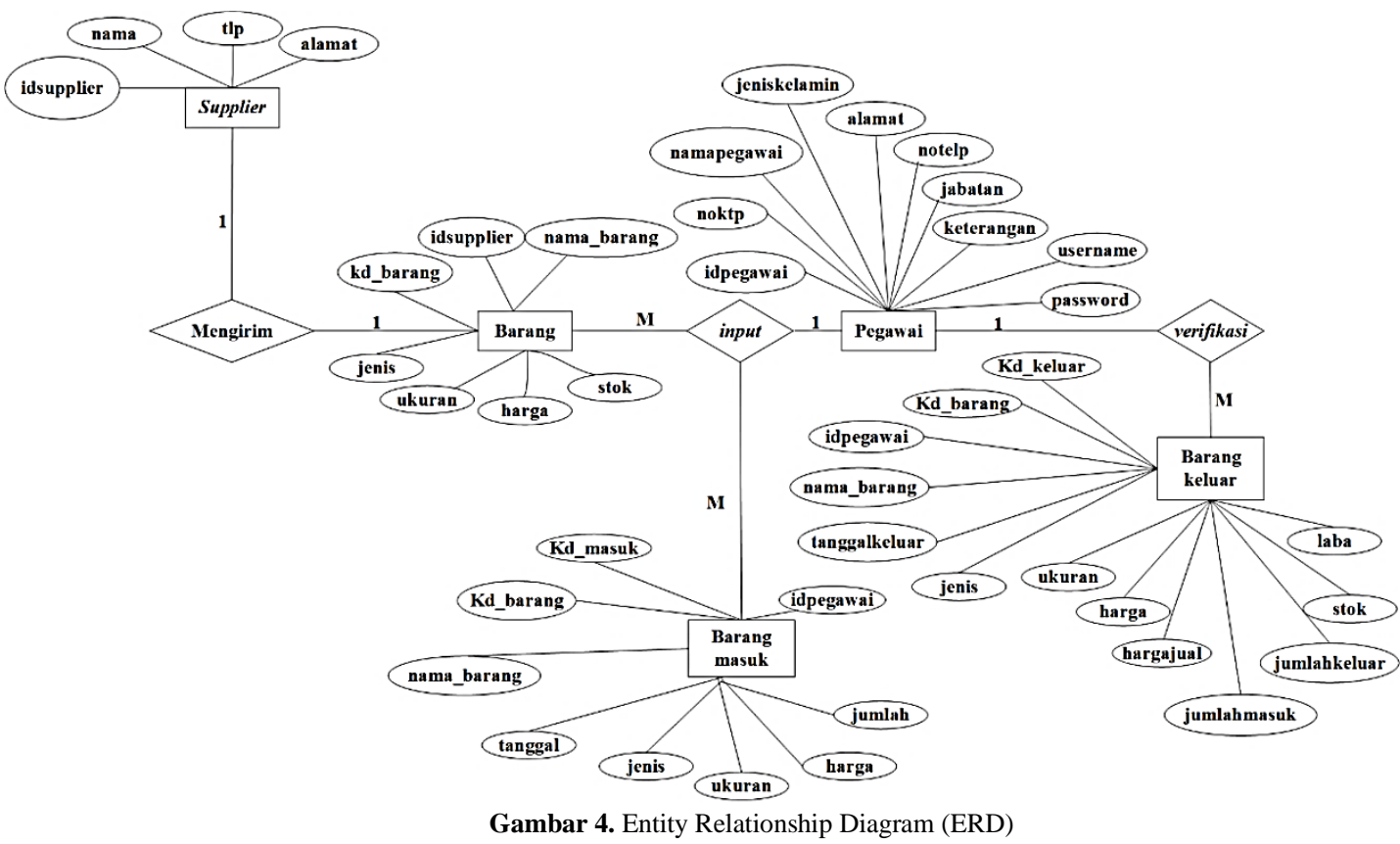

Pada Perancangan Aplikasi persediaan Sepatu Pada Gudang Melky Marilyn peneliti membuat dengan menggunakan java netbeans edisi 8.0.2 dan menggunakan database MySQL. Berikut ini adalah tampilan aplikasi pada Warehouse Melky Marilyn:

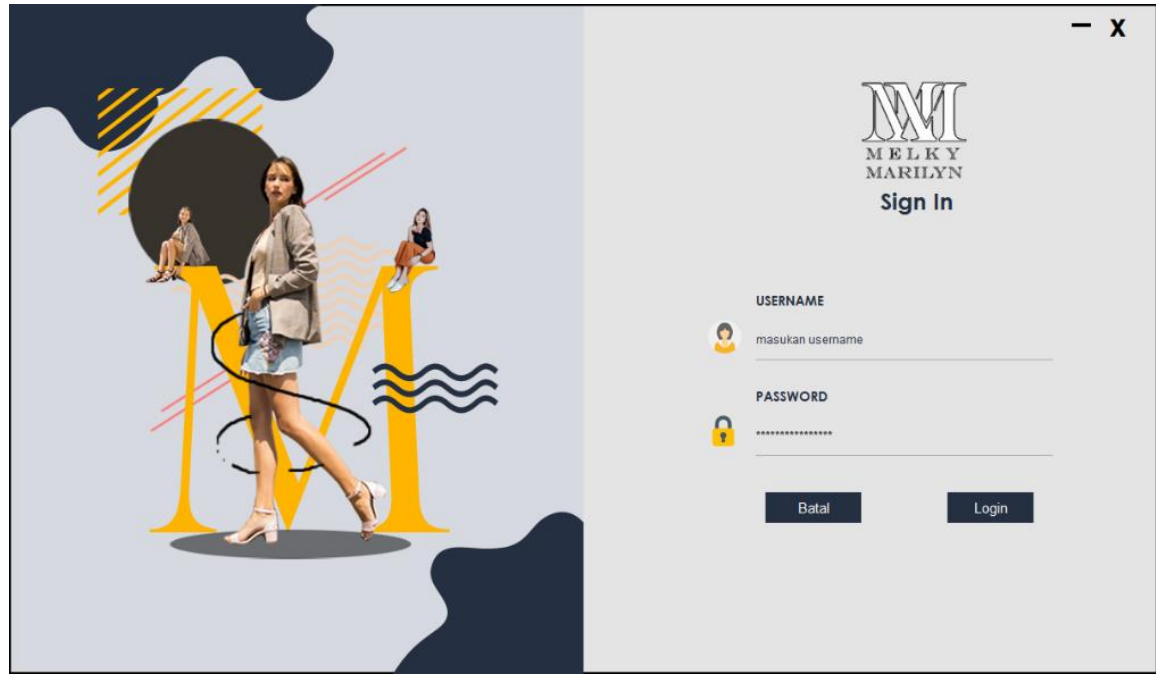

Gambar 5. Tampilan Layar Login

Tampilan menu login ini muncul diawal saat pengoperasian program aplikasi untuk diisi oleh admin gudang. Admin gudang memasukkan username dan password yang sesuai dengan hak akses supaya dapat mengoperasikan sistem. Jika admin menginput username dan password seperti pada gambar di atas dan username juga password sesuai, maka akan masuk ke tampilan menu utama. 


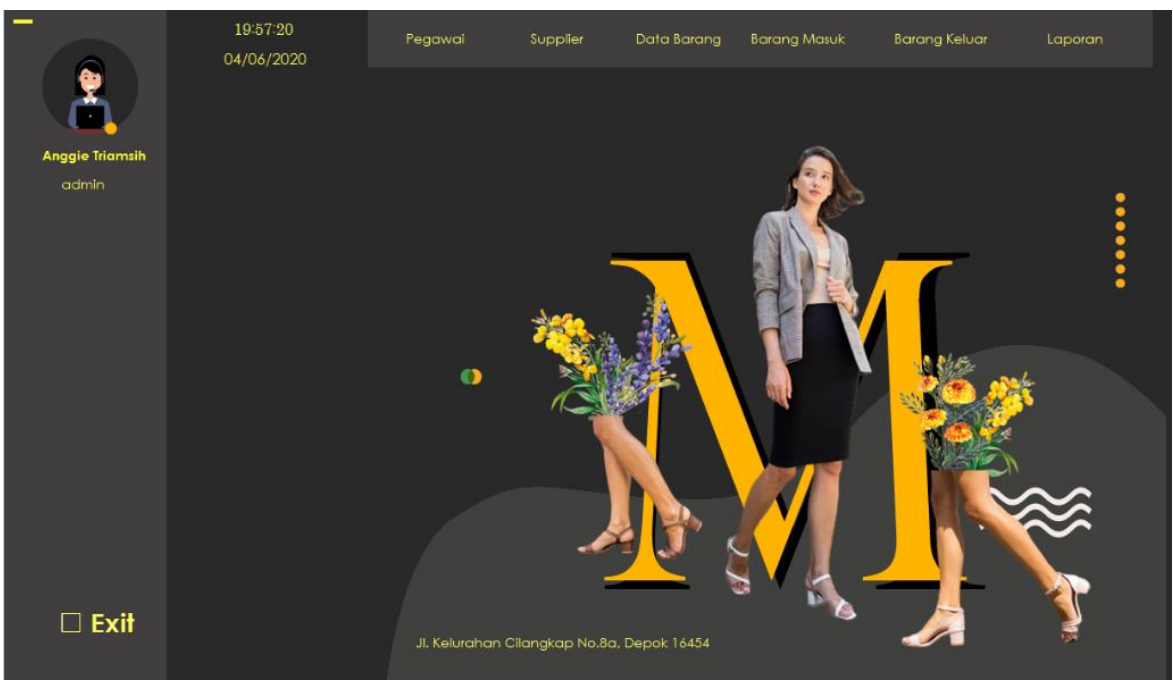

Gambar 6. Tampilan Layar Menu Utama

Tampilan menu utama ini terdapat beberapa menu bar yang akan menampilkan form-form masukan dan keluaran sebagai berikut:

a. Pada menu pegawai akan menampilkan form pegawai. Form pegawai berfungsi untuk menginput data pegawai baru yang belum terdaftar dalam sistem.

b. Pada menu supplier akan menampilkan form supplier. Form supplier berfungsi untuk menginput data supplier yang terdapat pada warehouse Melky Marilyn.

c. Menu data barang akan menampilkan form data barang.

d. Menu barang masuk akan manampilkan form barang masuk.

e. Menu barang keluar akan menampilkan form barang keluar.

f. Laporan akan menampilkan 5 keluaran yaitu laporan data.

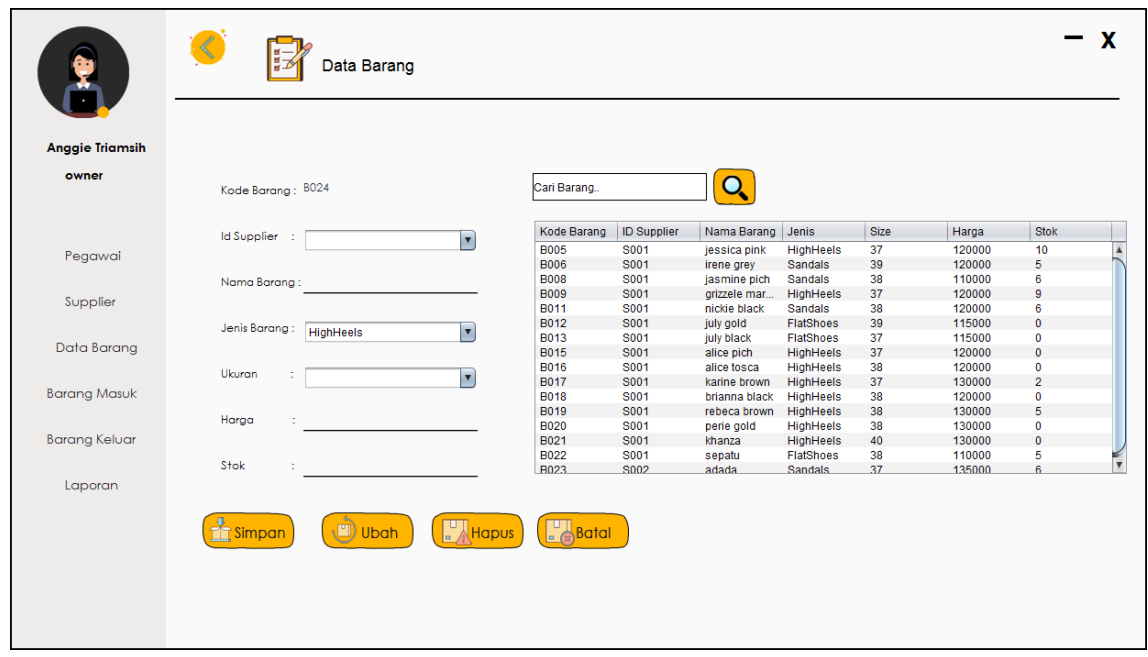

Gambar 7. Tampilan Menu Data Barang

Tampilan diatas merupakan tampilan menu data barang. Pada tampilan menu data barang admin dapat menambahkan data barang yang belum terdata dalam aplikasi, admin juga dapat mengubah data dan menghapusnya sesuai dengan kebutuhan. Dalam tampilan menu data barang juga terdapat button batal yang berfungsi untuk mengkosongkan field yang sebelumnya telah terisi, data yang di input dan disimpan oleh admin akan tersimpan pada database. 


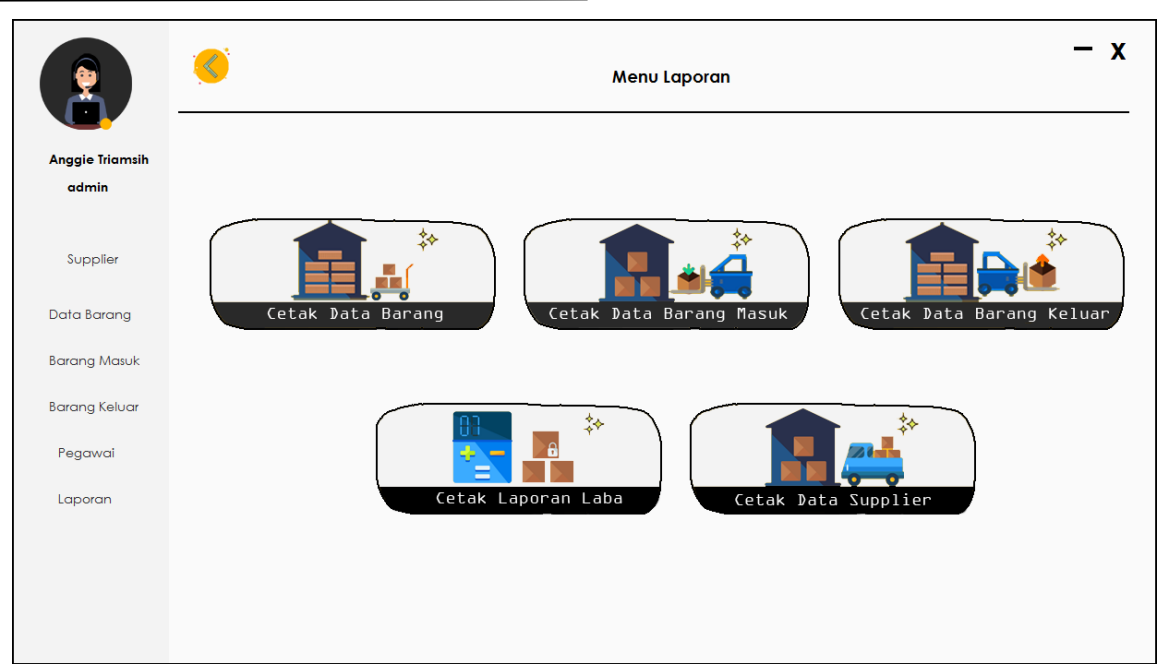

Gambar 8. Tampilan Menu Laporan

Pada menu laporan terdapat pilihan menu cetak laporan data barang, laporan data barang masuk, laporan data barang keluar, laporan laba, dan laporan data pemasok Jika salah satu tombol tersebut dipilih maka akan menampilkan data dari laporan tersebut.

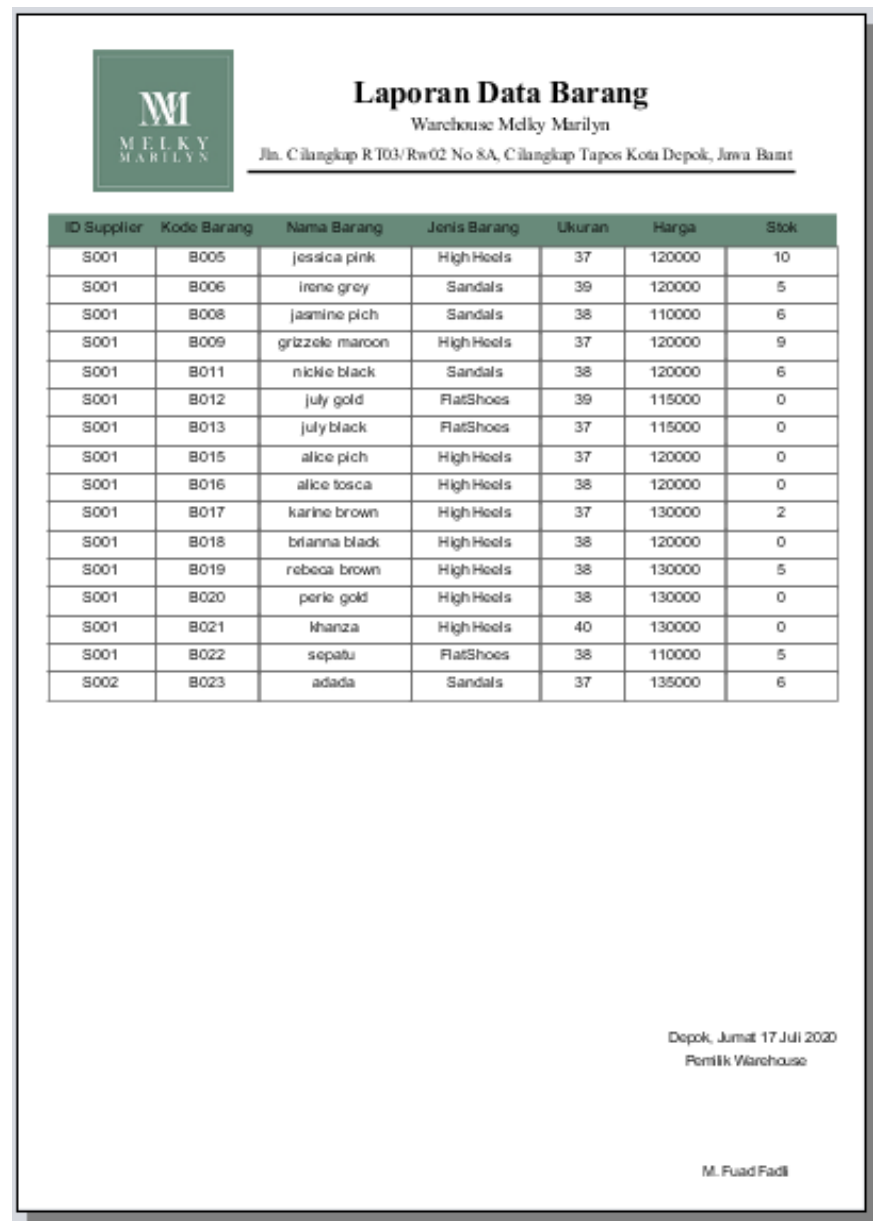

Gambar 9. Tampilan Laporan Data Barang

Tampilan laporan data barang berfungsi untuk menampilkan barang yang tersedia di gudang agar mempermudah untuk menambah stok bila ada barang yang tidak tersedia. Laporan dapat dicetak kapan saja sesuai dengan kebutuhan atau permintaan dari pemilik. 


\section{SIMPULAN}

Berdasarkan hasil penelitian tentang perancangan aplikasi inventory pada warehouse Melky Marilyn dapat disimpulkan bahwa :

1. Dengan adanya aplikasi ini proses pendataan barang masuk dan keluar akan lebih efisien karna akan terdata didalam sistem, dan lebih otomatis karena telah terkomputerisasi.

2. Aplikasi ini dirancang dengan harapan dapat mempermudah pihak gudang Melky Marilyn untuk mengelola data barang dan mengelola ketersediaan stok barang. Sehingga mengurangi resiko ketidaksediaan barang.

3. Dengan adanya aplikasi persediaan ini mampu mengurangi kehilangan data dan kekeliruan dalam mengolah data, karena data telah tersimpan dalam database.

\section{DAFTAR PUSTAKA}

Hays, R. N., Sugiyarta, A., \& Winungkas, D. E. (2018). Aplikasi Inventory Terintegrasi Order System Konsumen Pada Oto Bento Perumnas Cilegon Menggunakan Metode Waterfall. ProTekInfo(Pengembangan Riset Dan Observasi Teknik Informatika), 5(September), 22-25. https://doi.org/10.30656/protekinfo.v5i0.713

Indrajani. (2015). Database Design (Case Study All in One). Jakarta: PT Elex Media Komputindo.

Mardison. (2017). Perancangan Sistem Informasi Inventory Pada Alinia Mart Berbasis Multi User Dengan Java Netbeans Dan Mysql. Majalah Ilmiah Upi Yptk, 24(2), 2. Retrieved from http://lppm.upiyptk.ac.id/majalahilmiah/index.php/majalahilmiah/article/view/95

Nugraha, W., Syarif, M., \& Dharmawan, W. S. (2018). Penerapan Metode Sdlc Waterfall Dalam Sistem Informasi. Nugraha, Wahyu Syarif, Muhamad Weiskhy Steven Dharmawan, 03(01), 23-29.

Setiady, T., \& Rahmad, M. B. (2014). Perancangan Sistem Informasi Inventory Spare Part Elektronik Berbasis Web PHP. Jurnal Sarjana Teknik Informatika, 2(2), 10.

Veranita, S., \& Legowo, M. B. (2018). JURNAL RESTI Penerapan Metode Economic Order Quantity Pada, 2(3), 768774. Retrieved from http://journal.iaii.or.id/index.php/RESTI/article/view/355/110

Komputer, Wahana. (2012). Membangun Aplikasi Bisnis dengan Netbeans 7. Semarang: Andi Offset.

Ladjamudin, A. (2013). Analisis Dan Desain Sistem Informasi. Yogyakarta: Graha Ilmu.

Lubis, Mayang. (2018). Metodologi Penelitian. Yogyakarta: CV Budi Utama.

Lubis, A. (2016). Basis Data Dasar. Yogyakarta: DEEPUBLISH.

Muharto dan Arisandy, A. (2016). Mengatasi Kesulitan Mahasiswa Dalam Menyusun Proposal Penelitian. Yogyakarta: Depublish.

Pamungkas, C.A. (2017). Pengantar Dan Implementasi Basis Data. Yogyakarta: CV Budi Utama.

Rachmanisah, Meuthia. (2018). Pengembangan Perangkat Lunak dan Sistem Informasi. Bogor: PT Penerbit IPB Press.

Sartono, A. (2010). Menejemen Keuangan Teori Dan Aplikasi. Yogyakarta: BPFE.

Sommerville, Ian. (2011). Software Engineering (Rekayasa Perangkat Lunak). Jakarta: Erlangga.

Trisyanto. (2017). Analisis \& Perancangan Sistem Basis Data. Surabaya: Garuda Mas Sejahtera. 